\title{
Prediction of mechanical ventilation greater than 24 hours in critically ill obstetric patients: ten years of data from a tertiary teaching hospital in mainland China
}

Huiying Zhao ${ }^{1{ }^{*}+}$, Guangjie Wang ${ }^{1+}$, Jie Lyu ${ }^{1}$, Xiaohong Zhang ${ }^{2}$ and Youzhong $\mathrm{An}^{1 *}$

\begin{abstract}
Background: Maternal admission to the intensive care unit (ICU) during pregnancy or in the postpartum period is a marker of severe acute maternal morbidity. Mechanical ventilation is an important and basic method of maintaining life support in the ICU, but prolonged mechanical ventilation (PMV) is associated with a prolonged length of hospital stay and other adverse outcomes. Therefore, we conducted this retrospective study to describe morbidity and further try to identify the risk factors for PMV in critically ill obstetric women.

Methods: The clinical data were obtained from a single-centre retrospective comparative study of 143 critically ill obstetric patients at a tertiary teaching hospital in mainland China between January 1, 2009, and December 31, 2019. PMV was defined as a mechanical ventilation length of more than $24 \mathrm{~h}$. Clinical and obstetric parameters were collected to analyse the risk factors for PMV. Patients were separated into groups with and without PMV. Potential risk factors were identified by univariate testing. Multivariate logistic regression was used to evaluate independent predictors of PMV.
\end{abstract}

Results: Out of 29,236 hospital deliveries, 265 critically ill obstetric patients entered the ICU. One hundred forty-five (54.7\%) of them were treated with mechanical ventilation. Two were excluded because of death within $24 \mathrm{~h}$. Sixtyfive critically ill obstetric patients (45.5\%) underwent PMV. The independent risk factors for PMV included estimated blood loss (odds ratio $(O R)=1.296, P=0.029)$, acute kidney injury (AKI) $(\mathrm{OR}=4.305, P=0.013)$, myocardial injury (OR= 4.586, $P=0.012)$, and $\mathrm{PaO}_{2} / \mathrm{FiO}_{2}(\mathrm{OR}=0.989, P<0.001)$. The area under the receiver operating characteristic (ROC) curve based on the predicted probability of the logistic regression was 0.934 .

Conclusions: Estimated blood loss, $\mathrm{AKI}$, myocardial injury, and $\mathrm{PaO}_{2} / \mathrm{FiO}_{2}$ were independent risk factors for PMV in critically ill obstetric patients.

Keywords: Critically ill obstetric patients, Prolonged mechanical ventilation, Risk factors

\footnotetext{
*Correspondence: zhaohuiying109@sina.com; youzhonganicu@163.com

${ }^{\dagger}$ Huiying Zhao and Guangjie Wang contributed equally to this work.

'Department of Critical Care Medicine, Peking University People's Hospital,

No. 11 Xizhimen South Street, Xicheng District, Beijing 100044, China

Full list of author information is available at the end of the article
}

(C) The Author(s). 2021 Open Access This article is licensed under a Creative Commons Attribution 4.0 International License, which permits use, sharing, adaptation, distribution and reproduction in any medium or format, as long as you give appropriate credit to the original author(s) and the source, provide a link to the Creative Commons licence, and indicate if changes were made. The images or other third party material in this article are included in the article's Creative Commons licence, unless indicated otherwise in a credit line to the material. If material is not included in the article's Creative Commons licence and your intended use is not permitted by statutory regulation or exceeds the permitted use, you will need to obtain permission directly from the copyright holder. To view a copy of this licence, visit http://creativecommons.org/licenses/by/4.0/. The Creative Commons Public Domain Dedication waiver (http://creativecommons.org/publicdomain/zero/1.0/) applies to the data made available in this article, unless otherwise stated in a credit line to the data. 


\section{Background}

Although maternal deaths in China have decreased substantially in recent decades, the incidence of severe acute maternal morbidity (SAMM) is still high $[1,2]$. Due to the implementation of the two-child policy in China, since 2016, the number of pregnant women with an older maternal age and history of caesarean section has increased, which has further increased the incidence of gestational diabetes mellitus, dangerous placenta previa, placental implantation, and severe postpartum haemorrhage [3-5]. Maternal admission to the intensive care unit (ICU) during pregnancy or in the postpartum period is a marker of SAMM [2, 6-11]. ICU admission of pregnant and postpartum women presents significant challenges to ICU clinicians because of altered maternal physiology, fetal considerations and medical emergencies associated with pregnancy $[12,13]$. Mechanical ventilation is an important and basic manner of maintaining life support in the ICU, but prolonged mechanical ventilation (PMV) increases the risk of a prolonged length of hospital stay, increased hospitalization costs, and other adverse outcomes $[14,15]$. Therefore, exploring the risk factors for prolonged mechanical ventilation in critically ill pregnant and postpartum women is important for quality and prognosis improvement. However, little is known about the proportion and risk factors for PMV in critically ill obstetric patients. Therefore, we conducted this retrospective study to describe morbidity and further try to identify the risk factors for PMV in critically ill obstetric women.

\section{Methods \\ Participants}

The clinical data were obtained from a single-centre retrospective comparative study of 143 critically ill obstetric patients at a tertiary teaching hospital in mainland China between January 1, 2009, and December 31, 2019. The protocol for this study was approved by the institutional independent Ethics Committee.

The inclusion criteria for this study were obstetric patients (i.e., those who were pregnant or up to 42 days postpartum) with the following conditions: (1) entered the intensive care unit (ICU) and (2) treated with mechanical ventilation (MV). Obstetric patients who met the following criteria would be transferred to the ICU: patients requiring or likely to require advanced respiratory support, patients requiring support of two or more organ systems, and patients with chronic impairment of one or more organ systems who also require support for an acute reversible failure of another organ. The exclusion criteria were as follows: (1) age < 18 years; (2) those who signed do-not-resuscitate; and (3) death within $24 \mathrm{~h}$ of the commencement of MV.

\section{Baseline characteristics}

The baseline clinical and obstetric patient characteristics were collected within the first $24 \mathrm{~h}$ after mechanical ventilation (the worst results within the first $24 \mathrm{~h}$ were chosen) (see Table 1). Clinical parameters included age, causes for ICU admission, Acute Physiology and Chronic Health Evaluation (APACHE) II score, body mass index (BMI), creatinine, acute kidney injury (AKI), troponin $\mathrm{T}$, myocardial injury, total bilirubin (TBIL), albumin, brain natriuretic peptide (BNP), white blood cell (WBC) count, platelets arterial blood $\mathrm{pH}$, arterial partial pressure of carbon dioxide $\left(\mathrm{PaCO}_{2}\right)$, the ratio of the arterial partial pressure of oxygen and the fraction of inspired oxygen $\left(\mathrm{PaO}_{2} / \mathrm{FiO}_{2}\right)$, and lactate. Acute kidney injury (AKI) was identified according to the Kidney Disease: Improving Global Outcomes (KDIGO) definition as one of the following: 1) An increase in serum creatinine by $\geq 0.3 \mathrm{mg} / \mathrm{dl}$ $(\geq 26.5 \mu \mathrm{mol} / \mathrm{l})$ within $48 \mathrm{~h} ; 2)$ An increase in serum creatinine to $\geq 1.5$ times baseline within the previous 7 days; 3) Urine volume $\leq 0.5 \mathrm{ml} / \mathrm{kg} / \mathrm{h}$ for $6 \mathrm{~h}$ [16]. Myocardial injury was defined as an increase in blood cardiac troponin I with a cut-off value of $34 \mathrm{pg} / \mathrm{mL}$ in our hospital [17].

Obstetric parameters included gestational weeks, obstetric causes of ICU admission, and the estimated blood loss volume during delivery.

\section{Clinical outcomes}

The outcomes of the critically ill obstetric patients in our study included the length of ICU stay, length of hospital stay, length of mechanical ventilation, and hospital mortality.

\section{Prolonged mechanical ventilation}

Previous studies used predefined values of mechanical ventilation time, ranging from $24 \mathrm{~h}$ to $72 \mathrm{~h}$, and even to 21 days, to define critically ill patients as having PMV [18]. In this study, PMV was defined as a mechanical ventilation length of more than $24 \mathrm{~h}$. This definition was in accordance with some previous studies $[19,20]$ and also guided by the median length of mechanical ventilation of this study. According to PMV status, patients were divided into two groups: the PMV group and the non-PMV group. The ventilation principles and weaning protocol were listed in the additional files (see Additional file 2).

\section{Statistical analysis}

We evaluated the normality of the continuous variables and found that all data were abnormally distributed. Therefore, continuous data were expressed as medians with interquartile ranges. Categorical variables were expressed as proportions. In the univariate testing, continuous and categorical variables were examined using Kruskal-Wallis equality-of-populations rank tests or Pearson chi-square tests, respectively. Variables with a 
Table 1 Comparison of the clinical characteristics of the prolonged mechanical ventilation group and the non-prolonged mechanical ventilation group

\begin{tabular}{|c|c|c|c|c|}
\hline \multirow[t]{2}{*}{ Variables } & \multicolumn{3}{|c|}{ Median [IQR] / no. (\%) } & \multirow[b]{2}{*}{$P$ value } \\
\hline & Overall & PMV group & Non-PMV group & \\
\hline Number & 143 & 65 & 78 & \\
\hline Age, years & $31(28-36)$ & $31(28-34)$ & $31.5(28-36)$ & 0.226 \\
\hline $\mathrm{BMl}, \mathrm{kg} / \mathrm{m}^{2}$ & $27.8(24.3-30.1)$ & $27.0(23.9-29.4)$ & $28.3(25.4-30.4)$ & 0.178 \\
\hline Gestational weeks, weeks & $34.9(30.4-38)$ & $34.2(29.2-37.2)$ & $35(32-38)$ & 0.157 \\
\hline APACHE II score & $15(14-18)$ & $16(14-20)$ & $15(13-18)$ & 0.008 \\
\hline Causes of the admission of ICU, obstetric causes & $90(62.9 \%)$ & $46(70.8 \%)$ & $44(56.4 \%)$ & 0.077 \\
\hline Estimated blood loss, L & $1.1(0.4-3.9)$ & $2.8(0.7-6.3)$ & $0.7(0.3-2.4)$ & $<0.001$ \\
\hline Creatinine, $\mu \mathrm{mol} / \mathrm{L}$ & $60(44-93)$ & $88(56-127)$ & $51(41-64)$ & $<0.001$ \\
\hline AKI & $63(44.1 \%)$ & $48(73.9 \%)$ & 15 (19.2\%) & $<0.001$ \\
\hline Troponin I, pg/mL & $27(4-183)$ & $106(32-321)$ & $6(2-30)$ & $<0.001$ \\
\hline Myocardial injury & $61(42.7 \%)$ & 47 (72.3\%) & $14(18.0 \%)$ & $<0.001$ \\
\hline TBIL, $\mu \mathrm{mol} / \mathrm{L}$ & $14.8(9.5-27.4)$ & $20.2(11.1-39.2)$ & $12.4(8.3-22.6)$ & $<0.001$ \\
\hline Albumin, $g / L$ & $26.3(23-29.3)$ & $25.3(22.6-28.8)$ & $26.7(23.8-29.9)$ & 0.121 \\
\hline BNP, $p g / m L$ & $368(135-631)$ & $539(368-820)$ & $194(91-397)$ & $<0.001$ \\
\hline $\mathrm{WBC}, \times 10^{9} / \mathrm{L}$ & $13.6(10.1-16.2)$ & $13.2(9.7-16.1)$ & $13.7(10.7-16.2)$ & 0.557 \\
\hline Platelet, $\times 10^{12} / \mathrm{L}$ & $74(40-119)$ & 66 (37-97) & $88.5(53.1-138)$ & 0.026 \\
\hline $\mathrm{pH}$ & $7.4(7.4-7.5)$ & $7.4(7.4-7.5)$ & $7.4(7.4-7.5)$ & 0.406 \\
\hline $\mathrm{PaCO}_{2}, \mathrm{mmHg}$ & $31.9(27.4-35)$ & $33.3(28.6-36.8)$ & $30.6(27-34)$ & 0.008 \\
\hline Bicarbonate, $\mathrm{mmol} / \mathrm{L}$ & $22.3(19.7-24.1)$ & $23.1(20.7-25.2)$ & $21.2(19.2-24.1)$ & 0.071 \\
\hline $\mathrm{PaO}_{2} / \mathrm{FiO}_{2}, \mathrm{mmHg}$ & $322.3(223.5-441)$ & 240 (173.3-318.3) & $403.4(319.8-501.5)$ & $<0.001$ \\
\hline Lactate, mmol/L & $1.4(0.9-2.6)$ & $1.8(1.1-3.4)$ & $1.2(0.8-1.9)$ & 0.002 \\
\hline
\end{tabular}

Abbreviations: IQR interquartile ranges, $P M V$ prolonged mechanical ventilation, $B M I$ body mass index, APACHE acute physiology and chronic health evaluation, ICU intensive care unit, $A K I$ acute kidney injury, $B N P$ brain natriuretic peptide, $W B C$ white blood cell, $T B I L$ total bilirubin, no. Number, $P a C O_{2}$ arterial partial pressure of carbon dioxide, $\mathrm{PaO}_{2} / \mathrm{FiO}_{2}$ the ratio of the arterial partial pressure of oxygen and the fraction of inspired oxygen

significance of less than 0.05 on univariate analysis were identified as risk factors. We used the variance inflation factor (VIF) and tolerance to test the multicollinearity of the risk factors. A VIF more than 10 or tolerance less than 0.1 was identified as significant multicollinearity. Independent risk factors for PMV was determined by binary logistic regression. We used Hosmer-Lemeshow test to estimate the goodness of fit. We used predictive probability values from logistic regression to generate the receiver operating characteristic (ROC) curve. And the regression coefficients were plotted by the coefplot module. We used a nomogram to demonstrate the risk points and probability for predicting PMV. A $P$ value of less than 0.05 in 2-sided tests was the threshold for statistically significant. Analyses were performed with Stata software, version 15.1 (Stata Corp).

\section{Results}

\section{Participants}

Out of 29,236 hospital deliveries, 265 critically ill obstetric patients entered the ICU between January 1, 2009, and December 31, 2019, in our hospital. One hundred forty-five $(54.7 \%)$ of them were treated with mechanical ventilation. Two were excluded because of death within $24 \mathrm{~h}$ of the commencement of MV. Finally, one hundred forty-three patients were enrolled in this study (see Fig. 1). Among these patients, 52 (36.4\%) were transferred from other hospital and all of them gave birth at our hospital. Seven (4.9\%) of those patients were admitted during pregnancy and 136 (95.1\%) admitted postpartum.

The median age was 31 years, and the median gestational week was 34.9 weeks. Obstetric causes made up the majority of the causes of ICU admission (62.9\%, 90/ 143). The main obstetric cause was postpartum haemorrhage $(35 \%, 50 / 143)$. Other obstetric causes included eclampsia or pre-eclampsia $(18.9 \%, 27 / 143)$, puerperal infection $(5.6 \%, 8 / 143)$, acute fatty liver of pregnancy (AFLP) $(2.1 \%, 3 / 143)$ and others $(1.4 \%, 2 / 143)$. Nonobstetric causes included haematological diseases $(11.2 \%$, $16 / 143)$, autoimmune diseases $(5.6 \%, 8 / 143)$, cardiovascular disease $(2.1 \%, 3 / 143)$, neuropsychiatric diseases $(4.2 \%$, $6 / 143)$, acute pancreatitis $(3.5 \%, 5 / 143)$, gastrointestinal perforation $(3.5 \%, 5 / 143)$ and others $(7.0 \%, 10 / 143)$. The 


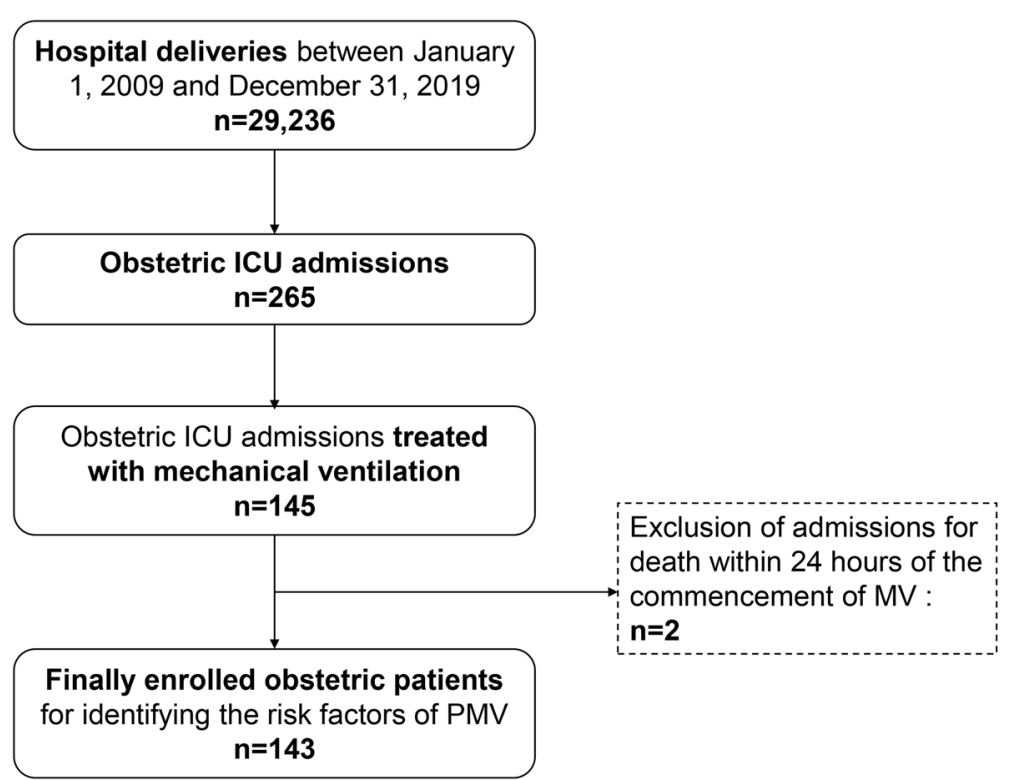

Fig. 1 Algorithm for selection of critically ill obstetric patients with mechanical ventilation

median length of mechanical ventilation was $19 \mathrm{~h}$. The median length of ICU stay and hospital stay were $72 \mathrm{~h}$ and 13 days, respectively. Four obstetric patients died in the hospital (2.8\%) (see Tables 1 and 2).

\section{Prolonged mechanical ventilation and outcomes}

Sixty-five critically ill obstetric patients $(45.5 \%)$ underwent PMV. The length of ICU stay $(P<0.001)$ and hospital stay $(P<0.001)$ were both significantly longer in the PMV group than in the non-PMV group. The mortality was very low, and there was no significant difference between the two groups $(P=0.229)$.

\section{Univariate analysis}

Compared with non-PMV patients, PMV patients had a higher APACHE II score $(P=0.008)$ and a larger amount of estimated blood loss during delivery $(P<0.001)$. The incidence of AKI $(P<0.001)$ and myocardial injury $(P<$ 0.001 ) was significantly higher in the PMV group than in the non-PMV group. PMV patients had significantly higher blood creatinine $(P<0.001)$, troponin $(P<0.001)$, TBIL $(P<0.001)$, BNP $(P<0.001), \mathrm{PaCO}_{2}(P=0.012)$, and lactate $(P=0.002)$ levels. The blood platelet count $(P=$ 0.026) and the arterial blood $\mathrm{PaO}_{2} / \mathrm{FiO}_{2}(P<0.001)$ were significantly lower in the PMV group. No significant difference in age, BMI, gestational weeks, causes of ICU admission, blood WBC count, blood albumin level, arterial blood $\mathrm{pH}$, or bicarbonate was observed (see Tables 1 and 2).

\section{Multivariate analysis}

Variables including APACHE II score, BMI, AKI, myocardial injury, TBIL, BNP, platelets, $\mathrm{PaCO}_{2}, \mathrm{PaO}_{2} / \mathrm{FiO}_{2}$, and estimated blood loss with a $P$ value of $<0.05$ in the univariate analysis were identified as risk factors for PMV. We tested the multicollinearity of all the risk factors. The results showed that the largest VIF was 1.66 and the smallest tolerance was 0.60 (see Additional file 1). Therefore, we included all 10 chosen risk factors in the logistic regression model, and we found that estimated

Table 2 Comparison of outcomes for the prolonged mechanical ventilation group and the non-prolonged mechanical ventilation group

\begin{tabular}{lllll}
\hline Outcomes & Median [IQR] / no. (\%) & & Non-PMV group & P \\
\cline { 2 - 4 } & Overall & PMV group & 65 & $31(23-67)$ \\
\hline Number & 143 & $168(99-312)$ & $11(8-16)$ & $<0.001$ \\
Length of ICU stay, hours & $72(27-168)$ & $15(12-26)$ & $1(1.3 \%)$ & $<0.001$ \\
Length of hospital stay, days & $13(9-20)$ & $3(4.6 \%)$ & 0.229 \\
Mortality & $4(2.8 \%)$ &
\end{tabular}

Abbreviation: IQR interquartile ranges, ICU intensive care unit, $P M V$ prolonged mechanical ventilation 
blood loss (L) (odds ratio $(\mathrm{OR})=1.296, P=0.029$ ), AKI $(\mathrm{OR}=4.305, P=0.013)$, myocardial injury $(\mathrm{OR}=4.586, P=$ 0.012), and $\mathrm{PaO}_{2} / \mathrm{FiO}_{2}$ (mmHg) (OR=0.989, $\left.P<0.001\right)$ were independent risk factors for PMV in critically ill obstetric patients (see Table 3). The Hosmer-Lemeshow test showed that the fit for the logistic regression model was good $(P=0.097$, chi $2=153.56)$. The ROC curve based on the predicted probability of the logistic regression is shown in Fig. 2, and the area under the curve was 0.934 (95\% CI, 0.895 to 0.974 ). The plot of the regression coefficients is shown in Fig. 3.

\section{Nomogram}

Through the logistic regression model, we built a prognostic nomogram incorporating the above independent prognostic factors for visualization and facilitation of clinical practice, as shown in Fig. 4. In this model, we transferred $\mathrm{PaO}_{2} / \mathrm{FiO}_{2}$ into four classes based on the Berlin definition of acute respiratory distress syndrome (ARDS) to simplify clinical practice [21].

\section{Discussion}

To our knowledge, this is the first study to identify the characteristics of mechanical ventilation and the risk factors for PMV in critically ill pregnant and postpartum patients. In our study, the incidence of mechanical ventilation was $54.7 \%$ among obstetric patients admitted to the ICU. Estimated blood loss, AKI, myocardial injury, and $\mathrm{PaO}_{2} / \mathrm{FiO}_{2}$ were independent risk factors for PMV in critically ill obstetric patients.

In our study, more than half of critically ill obstetric patients received mechanical ventilation, and $45.5 \%$ of them had a ventilation time of more than $24 \mathrm{~h}$. These results are similar to those of another multicentre report.

Table 3 Logistic regression of prolonged mechanical ventilation and clinical variables

\begin{tabular}{llll}
\hline Variables & OR & $\boldsymbol{P}$ value & $\mathbf{9 5 \%} \mathbf{C l}$ \\
\hline Estimated blood loss, L & 1.296 & 0.029 & $1.028-1.634$ \\
Myocardial injury & 4.596 & 0.012 & $1.394-15.159$ \\
$\mathrm{AKI}$ & 4.305 & 0.013 & $1.361-13.617$ \\
$\mathrm{PaO}_{2} / \mathrm{FiO}_{2}, \mathrm{mmHg}$ & 0.989 & $<0.001$ & $0.984-0.995$ \\
$\mathrm{APACHE} / \mathrm{score}$ & 1.080 & 0.207 & $0.958-1.216$ \\
$\mathrm{BNP}, \mathrm{pg} / \mathrm{mL}$ & 0.999 & 0.399 & $0.999-1.000$ \\
$\mathrm{TBIL}, \mu \mathrm{mol} / \mathrm{L}$ & 1.014 & 0.317 & $0.987-1.041$ \\
Platelet, $\times 10^{12} / \mathrm{L}$ & 1.002 & 0.647 & $0.995-1.009$ \\
Lactate, $\mathrm{mmol} / \mathrm{L}_{\text {PaCO }_{2}, \mathrm{mmHg}}^{1.229}$ & 0.349 & $0.798-1.894$ \\
\hline A & 1.040 & 0.457 & $0.938-1.152$ \\
\hline
\end{tabular}

Abbreviations: $A P A C H E$ acute physiology and chronic health evaluation, $A K I$ acute kidney injury, BNP brain natriuretic peptide, TBIL total bilirubin, $\mathrm{PaCO}_{2}$ arterial partial pressure of carbon dioxide, $\mathrm{PaO}_{2} / \mathrm{FiO}_{2}$ the ratio of the arterial partial pressure of oxygen and the fraction of inspired oxygen, OR odds ratio, $\mathrm{Cl}$ confidence interval
Zhao et al. enrolled 491 obstetric patients with ICU admissions from three tertiary hospitals in China. They found that $40 \%$ of the patients underwent intubation and mechanical ventilation, and the median length of mechanical ventilation was 1 day [2].

Our study showed that estimated blood loss was an independent risk factor for the development of PMV. Several studies have shown that the most common cause of pregnancy-related admission to the ICU is obstetric haemorrhage $[2,12]$. A multicentre study in China found that postpartum haemorrhage (170/491; 34.62\%) was the main reason for ICU admission [2]. Chantry et al. determined the reasons for pregnancy-related ICU admissions from all ICUs in France from 2006 to 2009. They enrolled 11,824 pregnancy-related ICU admissions and showed that the leading cause of transfer to ICUs was obstetric haemorrhage $(4043 ; 34.2 \%)$ [12]. We also found that postpartum haemorrhage was the main reason for ICU admission (87/143; 35\%). Possible reasons for the association of estimated blood loss and PMV included the following: massive obstetric haemorrhage that induced hypovolemic shock and tissue hypoperfusion and further caused lung injury; an independent, dosedependent relationship between blood transfusion and the subsequent development of acute lung injury; and massive haemorrhage and subsequent resuscitation leading to fluid overload, which is associated with pulmonary oedema and ventilator dependence [22, 23]. Surgical procedures for hemostasis including uterine artery ligation, uterine packing, and hysterectomy are usually used for managing the massive hemorrhage.

In our study, obstetric patients with an AKI were more likely to have PMV than those without an AKI. Ghauri et al. systematically reviewed the predictors of the need for PMV in adult patients admitted to ICUs for medical and surgical needs. They found that kidney dysfunction was one of the most significant independent predictors of the need for PMV [18]. Clark et al. retrospectively assessed $130 \mathrm{ICU}$ patients and showed that serum creatinine levels greater than $2.0 \mathrm{mg} / \mathrm{dL}$ were independently associated with PMV. They further validated their findings in a prospective trial. Acute kidney injury is one of the manifestations of insufficient organ perfusion [24]. On the other hand, kidney dysfunction can cause fluid accumulation and tissue oedema. Therefore, it is very important to monitor renal function and treat potential causes in critically ill obstetric patients in a timely manner.

Our results demonstrated that myocardial injury was an independent risk factor for the development of PMV. We defined myocardial injury as an increase in blood cardiac troponin I [17]. Myocardial injury may be caused by hypoperfusion, hypoxia, global ischaemia, surgery, and sepsis in noncardiac patients. Karpati et al. enrolled 55 parturients with severe postpartum haemorrhage and 


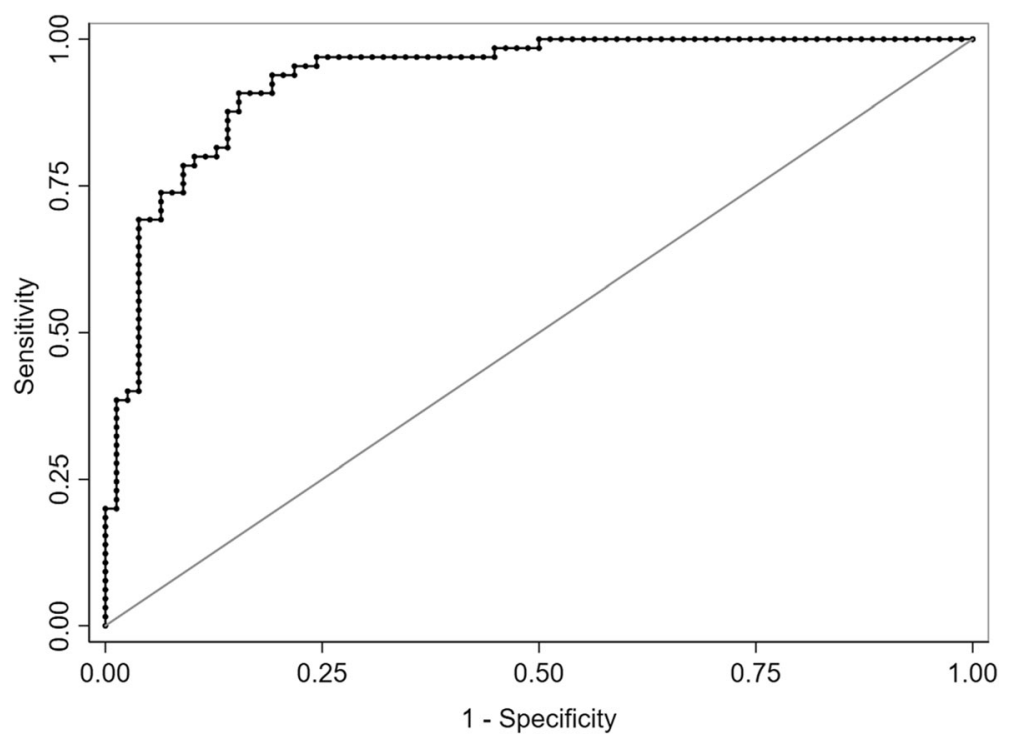

Fig. 2 The ROC curve using predicted probability values from the logistic regression. The area under the curve was $0.934,95 \% \mathrm{Cl}$ was 0.895 to 0.974

haemorrhagic shock and found that $51 \%$ of them had myocardial injury (elevated serum levels of cardiac troponin I). They also identified low systolic and diastolic arterial blood pressure $(<88$ and $<50 \mathrm{mmHg}$, respectively) and increased heart rate ( $>115$ beats $/ \mathrm{min})$ as independent predictors of myocardial injury [25]. A systematic review included nine studies involving 719 patients who suffer from pre-eclampsia and concluded that in such pre-eclampsia pregnant women cardiac troponin I might be elevated [26]. Previous studies also showed that myocardial injury was associated with mortality among patients undergoing noncardiac surgery $[17,27$, 28]. Our previous study retrospectively enrolled 381 critically ill patients who underwent major abdominal surgery. We found that myocardial injury is an independent risk factor for weaning failure from mechanical ventilation [29]. Abdalla et al. also demonstrated that troponin elevation was associated with a longer duration of mechanical ventilation in patients who were admitted to the ICU with sepsis [27].

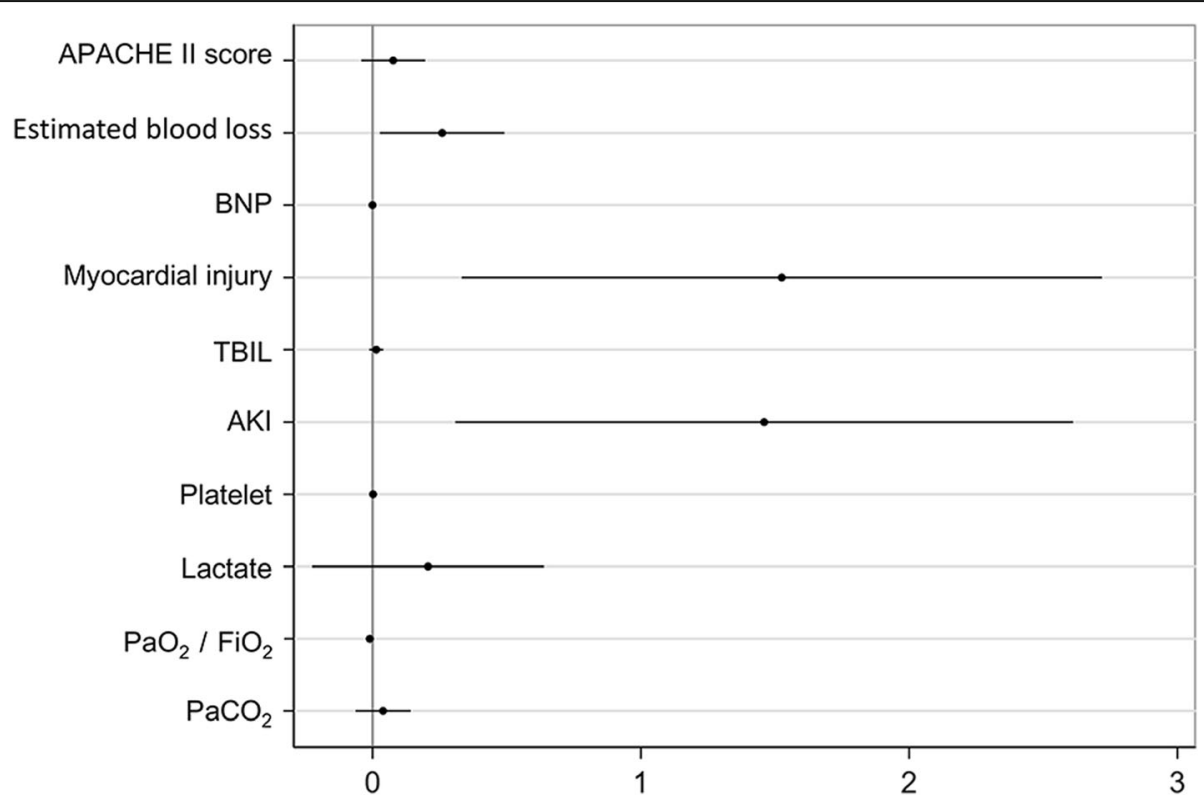

Fig. 3 Coefplot of the Logistic regression coefficient. Estimated blood loss, AKI, and myocardial injury were independent risk factors for PMV, but $\mathrm{PaO}_{2} / \mathrm{FiO}_{2}$ was independent protective factor 


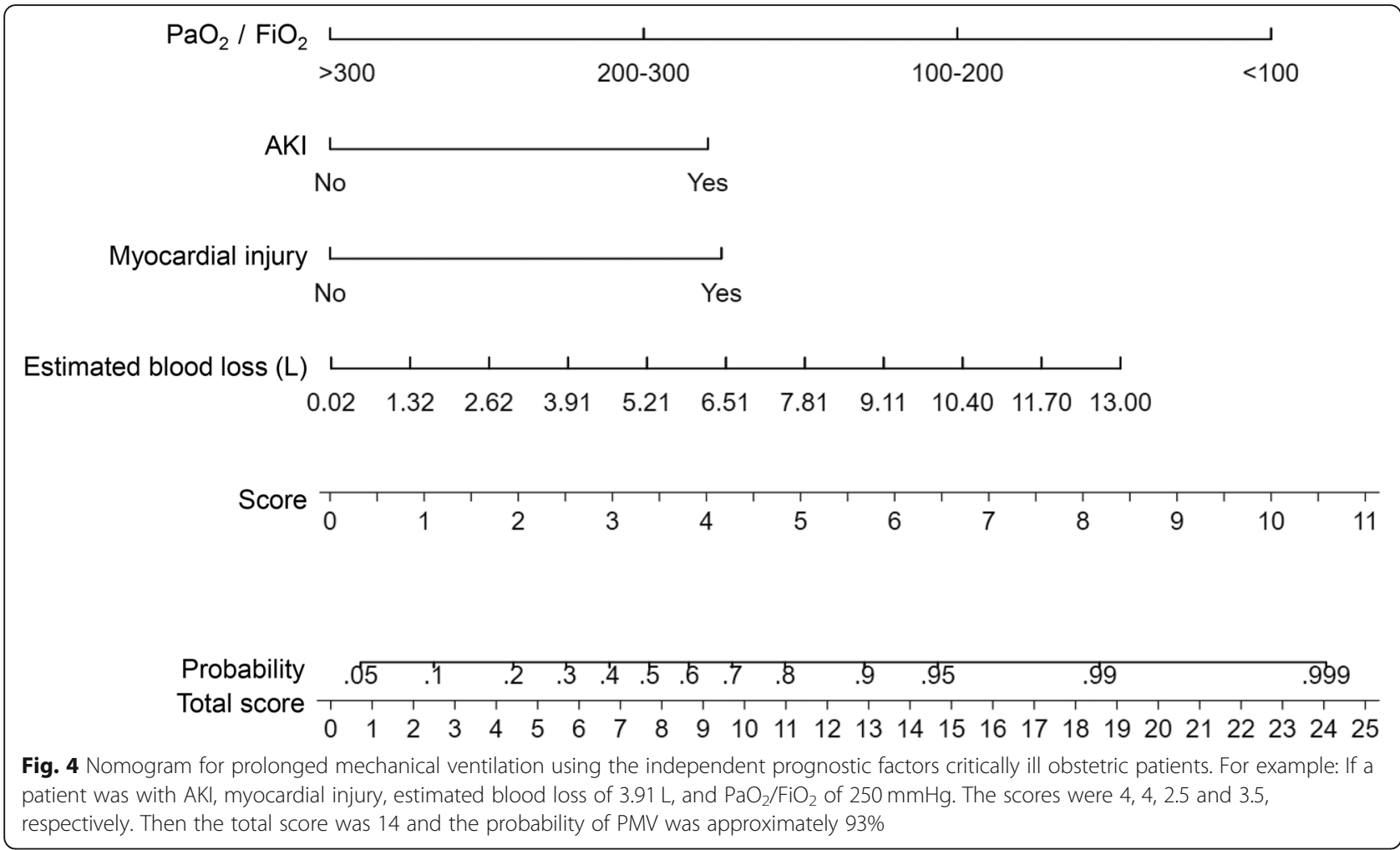

According to our logistic regression analysis, $\mathrm{PaO}_{2} /$ $\mathrm{FiO}_{2}$ is an independent risk factor for the development of PMV. $\mathrm{PaO}_{2} / \mathrm{FiO}_{2}$ is an important variable for evaluating lung injury, and it is the basis for the Berlin definition of ARDS risk stratification [21]. $\mathrm{PaO}_{2} / \mathrm{FiO}_{2}$ is also an important indicator for evaluating mechanical ventilation weaning [30]. Therefore, we need to monitor $\mathrm{PaO}_{2} / \mathrm{FiO}_{2}$ to evaluate the lung function of critically ill obstetric patients and improve $\mathrm{PaO}_{2} / \mathrm{FiO}_{2}$ through mechanical ventilation and other aetiological treatments.

We found that not only the pulmonary function parameter $\mathrm{PaO}_{2} / \mathrm{FiO}_{2}$ was a risk factor for PMV, but also estimated blood loss, AKI, and myocardial injury were independent risk factors. Therefore, the following measures are crucially important in clinical practice so as to shorten the length of mechanical ventilation: 1) early recognize and timely control the obstetric haemorrhage; 2) maintain hemodynamic stability and tissue perfusion to prevent organ dysfunction; 3) closely monitor the function of kidney, heart, and other organs in critically ill obstetric patients; 4) use lung-protective ventilation in lung injury patients $\left(\mathrm{PaO}_{2} / \mathrm{FiO}_{2}<300 \mathrm{mmHg}\right)$. In summary, the pre-ICU admission phase is very important and worthy of further research to shorten the mechanical ventilation time of critically ill obstetric patients.
This study has several limitations. First, the data were retrospectively collected. We could not control for some variables, which may have resulted in data bias. Second, the study was a single-centre study, and most obstetric patients were admitted to the ICU based on local criteria and local practice. Third, we did not distinguish the patients between pregnant and postpartum phase. Fourth, we did not analysis the data or the potential influence of transfusion of blood products. Fifth, most of the clinical parameters we included were collected after admission to ICU, so this study may have a delay in recognition of clinical deterioration. Sixth, we derived four independent risk factors for prolonged mechanical ventilation and built a nomogram for visualization and facilitation of clinical practice. However, we did not validate the nomogram with a new database. A prospective, multicentre study is needed to address these issues and validate our findings.

\section{Conclusions}

This retrospective study shows that the independent risk factors for PMV in critically ill obstetric patients are estimated blood loss, AKI, myocardial injury, and $\mathrm{PaO}_{2} /$ $\mathrm{FiO}_{2}$. The pre-ICU admission phase is worthy of further research to shorten the mechanical ventilation time of critically ill obstetric patients. 


\section{Supplementary Information}

The online version contains supplementary material available at https://doi. org/10.1186/s12884-020-03524-4.

Additional file 1. Multicollinearity test of risk factors for prolonged mechanical ventilation

Additional file 2. Ventilation principles. Ventilator Weaning Protocol.

\section{Abbreviations}

AFLP: Acute fatty liver of pregnancy; AKI: Acute kidney injury; APACHE: Acute physiology and chronic health evaluation; ARDS: Acute respiratory distress syndrome; BMI: Body mass index; BNP: Brain natriuretic peptide;

Cl: Confidence interval; ICU: Intensive care unit; IQR: Interquartile ranges; KDIGO: Kidney Disease: Improving Global Outcomes; MV: Mechanical ventilation; OR: Odds ratio; $\mathrm{PaCO}_{2}$ : Arterial partial pressure of carbon dioxide; $\mathrm{PaO}_{2} / \mathrm{FiO}_{2}$ : Ratio of arterial partial pressure of oxygen and fraction of inspired oxygen; PMV: Prolonged mechanical ventilation; ROC: Receiver operating characteristic; SAMM: Severe acute maternal morbidity; TBIL: Total bilirubin (TBIL); WBC: Blood white blood cell; VIF: Variance inflation factor

\section{Acknowledgements}

We would like to acknowledge the significant contribution of the patients, families, researchers, clinical staff, and sponsors included in this study.

\section{Authors' contributions}

$\mathrm{HZ}$ conceived of and designed the study, collected the data, performed the statistical analysis, interpreted the results, and drafted the manuscript. GW collected the data and helped in drafting the manuscript. $J$ participated in data collecting and manuscript revising. XZ participated in the study design and manuscript revising. YA participated in study design and coordination, and revised the manuscript. All authors read and approved of the final manuscript for publication.

\section{Funding}

HZ was supported partially by research fund provided by Peking University People's Hospital Research and Development Funds (No. RDY2019-43, derive sepsis phenotypes using electronic medical data and machine learning). This funding was not involved in the data collection, data analysis, or the preparation or editing of the manuscript.

\section{Availability of data and materials}

The authors declare that all data supporting the findings of this study are available within the article and its additional Files.

\section{Ethics approval and consent to participate}

The study was approved by Ethics Committee of Peking University People's Hospital. This study was in accordance with the ethical standards of the institutional research committee, the 1964 Helsinki declaration, and its later amendments. For this type of study formal consent is not required.

\section{Consent for publication}

Not applicable.

\section{Competing interests}

The authors declare that they have no competing interests.

\section{Author details}

'Department of Critical Care Medicine, Peking University People's Hospital, No. 11 Xizhimen South Street, Xicheng District, Beijing 100044, China. 2Department of Obstetrics, Peking University People's Hospital, No. 11 Xizhimen South Street, Xicheng District, Beijing 100044, China.

Received: 3 June 2020 Accepted: 22 December 2020

Published online: 09 January 2021

\section{References}

1. Tan J, Chen M, Li Y, Liu X, Yu C, Sun X. Modeling to predict severe maternal morbidity based on 33993 deliveries of registered study in China. Value Health. 2014;17:A750.
2. Zhao Z, Han S, Yao G, Li S, Li W, Zhao Y, et al. Pregnancy-related ICU admissions from 2008 to 2016 in China: a first multicenter report. Crit Care Med. 2018;46:e1002-9.

3. Zhang HX, Zhao YY, Wang YQ. Analysis of the Characteristics of Pregnancy and Delivery before and after Implementation of the Two-child Policy. Chin Med J (Engl). 2018;131:37-42.

4. Li HT, Luo S, Trasande L, Hellerstein S, Kang C, Li JX, et al. Geographic variations and temporal trends in cesarean delivery rates in China, 20082014. JAMA. 2017:317:69-76.

5. Lin L, Chen YH, Sun W, Gong JJ, Li P, Chen JJ, et al. Risk factors of obstetric admissions to the intensive care unit: An 8-year retrospective study. Medicine (Baltimore). 2019;98:e14835.

6. Ozcelik M, Turhan S, Bermede O, Yilmaz AA, Unal N, Bayar MK. Outcomes of antepartum and postpartum obstetric admissions to the intensive care unit of a Tertiary University hospital: An 8-year review. Turk J Anaesthesiol Reanim. 2017;45:303-9.

7. Pollock W, Rose $\mathrm{L}$, Dennis CL. Pregnant and postpartum admissions to the intensive care unit: a systematic review. Intensive Care Med. 2010;36:1465-74.

8. Romano DN, Hyman J, Katz D, Knibbs N, Einav S, Resnick O, et al. Retrospective analysis of obstetric intensive care unit admissions reveals differences in etiology for admission based on mode of conception. Anesth Analg. 2020;130:436-44.

9. Vargas M, Marra A, Buonanno P, lacovazzo C, Schiavone V, Servillo G. Obstetric admissions in ICU in a tertiary care center: a 5-years retrospective study. Indian J Crit Care Med. 2019;23:213-9.

10. Wanderer JP, Leffert LR, Mhyre JM, Kuklina EV, Callaghan WM, Bateman BT. Epidemiology of obstetric-related ICU admissions in Maryland: 1999-2008* Crit Care Med. 2013:41:1844-52.

11. Chantry AA, Deneux-Tharaux C, Bonnet MP, Bouvier-Colle MH. Pregnancyrelated ICU admissions in France: trends in rate and severity, 2006-2009. Crit Care Med. 2015;43:78-86

12. Afessa B, Green B, Delke I, Koch K. Systemic inflammatory response syndrome, organ failure, and outcome in critically ill obstetric patients treated in an ICU. Chest. 2001;120:1271-7.

13. Guntupalli KK, Hall N, Karnad DR, Bandi V, Belfort M. Critical illness in pregnancy: part I: an approach to a pregnant patient in the ICU and common obstetric disorders. Chest. 2015;148:1093-104.

14. Maclntyre NR, Epstein SK, Carson S, Scheinhorn D, Christopher K, Muldoon S. Management of patients requiring prolonged mechanical ventilation: report of a NAMDRC consensus conference. Chest. 2005;128:3937-54.

15. Lone NI, Walsh TS. Prolonged mechanical ventilation in critically ill patients: epidemiology, outcomes and modelling the potential cost consequences of establishing a regional weaning unit. Crit Care. 2011;15:R102.

16. Khwaja A. KDIGO clinical practice guidelines for acute kidney injury. Nephron Clin Pract. 2012;120:c179-84.

17. Botto F, Alonso-Coello P, Chan MT, Villar JC, Xavier D, Srinathan S, et al. Myocardial injury after noncardiac surgery: a large, international, prospective cohort study establishing diagnostic criteria, characteristics, predictors, and 30-day outcomes. Anesthesiology. 2014;120:564-78.

18. Ghauri SK, Javaeed A, Mustafa KJ, Khan AS. Predictors of prolonged mechanical ventilation in patients admitted to intensive care units: A systematic review. Int J Health Sci (Qassim). 2019;13:31-8.

19. Légaré JF, Hirsch GM, Buth KJ, MacDougall C, Sullivan JA. Preoperative prediction of prolonged mechanical ventilation following coronary artery bypass grafting. Eur J Cardiothorac Surg. 2001;20:930-6.

20. Natarajan K, Patil S, Lesley N, Ninan B. Predictors of prolonged mechanical ventilation after on-pump coronary artery bypass grafting. Ann Card Anaesth. 2006;9:31-6.

21. Ranieri VM, Rubenfeld GD, Thompson BT, Ferguson ND, Caldwell E, Fan E, et al. Acute respiratory distress syndrome: the Berlin definition. JAMA. 2012;307:2526-33.

22. Sentilhes L, Merlot B, Madar H, Sztark F, Brun S, Deneux-Tharaux C. Postpartum haemorrhage: prevention and treatment. Expert Rev Hematol. 2016;9:1043-61.

23. Benson AB, Moss M, Silliman CC. Transfusion-related acute lung injury (TRAL I): a clinical review with emphasis on the critically ill. Br J Haematol. 2009; 147:431-43.

24. Clark PA, Lettieri CJ. Clinical model for predicting prolonged mechanical ventilation. J Crit Care. 2013;28:880 e881-887.

25. Karpati PC, Rossignol M, Pirot M, Cholley B, Vicaut E, Henry P, et al. High incidence of myocardial ischemia during postpartum hemorrhage. Anesthesiology. 2004;100:30-6. 
26. Pergialiotis V, Prodromidou A, Frountzas M, Perrea DN, Papantoniou N. Maternal cardiac troponin levels in pre-eclampsia: a systematic review. J Matern Fetal Neonatal Med. 2016;29:3386-90.

27. Abdalla M, Sohal S, Al-Azzam B, Mohamed W. Effect of troponin I elevation on duration of mechanical ventilation and length of intensive care unit stay in patients with Sepsis. J Clin Med Res. 2019;11:127-32.

28. Devereaux PJ, Biccard BM, Sigamani A, Xavier D, Chan MTV, Srinathan SK, et al. Association of Postoperative High-Sensitivity Troponin Levels with Myocardial Injury and 30-day mortality among patients undergoing noncardiac surgery. JAMA. 2017;317:1642-51.

29. Li S, An YZ, Ren JY, Zhu FX, Chen H. Myocardial injury after surgery is a risk factor for weaning failure from mechanical ventilation in critical patients undergoing major abdominal surgery. PLoS One. 2014;9:e113410.

30. Schmidt GA, Girard TD, Kress JP, Morris PE, Ouellette DR, Alhazzani W, et al. Official executive summary of an American Thoracic Society/American College of Chest Physicians Clinical Practice Guideline: liberation from mechanical ventilation in critically ill adults. Am J Respir Crit Care Med. 2017;195:115-9.

\section{Publisher's Note}

Springer Nature remains neutral with regard to jurisdictional claims in published maps and institutional affiliations.

Ready to submit your research? Choose BMC and benefit from:

- fast, convenient online submission

- thorough peer review by experienced researchers in your field

- rapid publication on acceptance

- support for research data, including large and complex data types

- gold Open Access which fosters wider collaboration and increased citations

- maximum visibility for your research: over $100 \mathrm{M}$ website views per year

At BMC, research is always in progress.

Learn more biomedcentral.com/submissions 